\section{Stereotactic and Functional Neurosurgery}

\title{
Nigral Degeneration with Inclusion Body Formation and Behavioral Changes in Rats after Proteasomal Inhibition
}

\author{
Chaoshi Niu ${ }^{a, b}$ Jiaming Mei ${ }^{a, b}$ Qi Pan ${ }^{b} \quad$ Xianming Fu ${ }^{a}$ \\ a Department of Neurosurgery, Anhui Provincial Hospital, Affiliated to Anhui Medical University, and \\ ${ }^{b}$ Molecular Neurobiology and Neural Regeneration and Repairing Laboratory, \\ Anhui Provincial Stereotactic Neurosurgical Institute, Hefei City, Anhui Province, China
}

\section{Key Words}

Parkinson's disease $\cdot$ Proteasome inhibitor $\cdot$ Behavior .

Pathology $\cdot$ Inclusion body $\cdot$ Neurodegeneration

\begin{abstract}
Objective: We were interested in studying nigral degeneration with inclusion body formation and behavioral changes in rats after proteasomal inhibition. Methods: Observation of progressive behavioral and pathological changes in rats following a unilateral nigral injection of lactacystin, a selective proteasome inhibitor. Results: After administration at a concentration of $10 \mu \mathrm{g}(2 \mu \mathrm{l})$ of lactacystin, when tyrosine hydroxylase (TH) immunostaining decreased gradually in the substantia nigra pars compacta ( $\mathrm{SNc}$ ) and corpus striatum, $\alpha$-synuclein-immunopositive inclusion appeared extensively in the surviving neurons. We also observed the degeneration of diverse cellular organelles by transmission electron microscopy. The effect of cellular organelle degeneration on behavior, a clinical index, was striking and was statistically significant. Over the 3 weeks following the administration of lactacystin, a highly significant decrease in TH immunostaining was observed and $\alpha$-synuclein-immunopositive inclusions gradually appeared. Interestingly, there was a strong correlation in behavioral changes and the increase in $\alpha$-synuclein-immunopositive inclusions whereas the decrease in $\mathrm{TH}$ immunostaining did not seem to induce
\end{abstract}

any behavioral changes. Conclusions: Our results reveal that unilateral nigral proteasome inhibition induces degeneration in the SNc and corpus striatum as well as behavioral changes demonstrating strong time dependence. Behavioral changes were driven by the formation of $\alpha$-synuclein inclusions, but not by decreased TH neurons.

Copyright $\odot 2009$ S. Karger AG, Basel

\section{Introduction}

Parkinson's disease (PD), which affects $1-2 \%$ of the population over age 65 , is the most common neurodegenerative movement disorder. The classical form of the disease is characterized clinically by resting tremor, bradykinesia, rigidity, and postural instability $[1,2]$. Its pathological hallmarks are the selective and progressive loss of dopaminergic neurons of the substantia nigra pars compacta $(\mathrm{SNc})$ and the presence of intraneuronal proteinaceous inclusions known as Lewy bodies within the surviving neurons of the substantia nigra [3]. Although the clinical and pathological phenotype is well-described and clear, the etiology and pathogenesis of PD remain elusive. Recent studies suggest that proteasomal dysfunction may play an important role in the pathogenesis of PD $[1,4-9]$.

\section{KARGER}

Fax +4161306 1234 E-Mail karger@karger.ch www.karger.com
(C) 2009 S. Karger AG, Basel

1011-6125/09/0872-0069\$26.00/0

Accessible online at:

www.karger.com/sfn
Chaoshi Niu

Department of Neurosurgery, Anhui Provincial Hospital

Affiliated to Anhui Medical University, Lujiang Road 17

Hefei City, Anhui Province, PO Box 230001 (China)

Tel. +86 551228 3483, Fax +86551228 3997, E-Mail niuchaoshi@163.com 
Proteasome is a multisubunit protease complex that is implicated in the degradation of unwanted proteins in eukaryotic cells. According to several recent studies, the activity of proteasomes in the SNc of PD patients is decreased [4-6]. Consistently, a number of other recent studies showed that proteasome inhibitors could induce selective degeneration of dopaminergic cells in culture and nigrostriatal degeneration with motor dysfunction when injected directly into the $\mathrm{SNc}$ or striatum of rats [7-10]. These researches shed new light on the pathogenesis of PD, and new animal models of PD were devised.

In the present study, our objective was to examine the effects of lactacystin, a selective proteasome inhibitor, on the nigrostriatal dopamine system and the behaviors of rats following unilateral injection of lactacystin into the $\mathrm{SNc}$ and to investigate whether behavioral and histopathological changes were correlated.

\section{Materials and Methods}

\section{Animals}

Male Sprague-Dawley rats weighing 200-250 g were obtained from Anhui Medical University (Hefei city, China). The animals received food and water ad libitum and were kept under strictly controlled environmental conditions ( $12 \mathrm{~h} \mathrm{light/dark} \mathrm{cycle,} \mathrm{with}$ light on between 7.00 and $19.00 \mathrm{~h}$; room temperature $21^{\circ} \mathrm{C}$ ). During all of the experimental procedures, the rats were treated in accordance with the Guidelines for Animal Care and Use of the National Institutes of Health.

\section{Surgery and Microinfusions}

Rats were deeply anesthetized with chloral hydrate $(300 \mathrm{mg} /$ $\mathrm{kg}$, i.p.) and placed in a Kopf stereotaxic apparatus (Narishige, Japan). An injection cannula (a 30-gauge stainless-steel cannula connected to a Hamilton $10-\mu l$ syringe driven by a microinfusion pump) was slowly inserted through a hole drilled into the skull into the central part of the left SNc of each animal using the following coordinates (in millimeters): anteroposterior -5.2 ; mediolateral \pm 2.2 ; dorsoventral -7.2 [11]. Lactacystin, the specific proteasome inhibitor (Sigma-Aldrich Corp., St. Louis, Mo., USA), was injected into the left $\mathrm{SNc}(\mathrm{n}=52,28$ were infused with lactacystin, 12 were infused with saline as control, and 12 were sham-operated on the left side) whereas the contralateral side was left intact. Infusions were performed during surgery; lactacystin was dissolved in physiological saline $(10 \mu \mathrm{g} / 2 \mu \mathrm{l})$ and delivered at a flow rate of 0.5 $\mu \mathrm{l} / \mathrm{min}$ for $4 \mathrm{~min}$. The cannula was slowly removed after the infusion and the incision was tightly closed after $5 \mathrm{~min}$.

\section{Behavioral Analysis}

After the injection, the rats were examined for spontaneous behavioral abnormalities, and assessed by apomorphine (APO, Sigma-Aldrich Corp.)-induced rotational asymmetry during 30 min. Rotational behavior was tested in rotometer bowls after APO administration. The number of rotations to the ipsilateral side was counted $10 \mathrm{~min}$ for $30 \mathrm{~min}$ after an intraperitoneal adminis- tration of APO $(0.5 \mathrm{mg} / \mathrm{kg})$. All rats without APO injection were tested simultaneously in the open field, which consisted of a black wooden chamber $(60 \times 60 \times 40 \mathrm{~cm})$ with a black floor divided into 25 grids. Testing was carried out under dim red light between 5.00 and $22.00 \mathrm{~h}$; each rat was video-recorded for $15 \mathrm{~min}$. The recordings were evaluated by an investigator who was unaware of the treatment. Behavioral tests were focused on two groups of signs: hypokinetic and asymmetrical signs [12]. Hypokinetic behavioral signs were measured by shuttling distance and total time of ambulation and ceasing. Asymmetrical behavioral signs were measured by the number of spontaneous left and right quarter turns (i.e. within a diameter of $30 \mathrm{~cm}$ ) [13] and the number of left and right forelimb uses when resting against the wall in rearing [14]. Active thigmotactic scanning, e.g. the number of times the animal ran along the walls (within $5 \mathrm{~cm}$ from the wall) of the open field with its left or right side was also recorded [15]. These parameters were analyzed starting $10 \mathrm{~s}$ after the animals were placed into the open field.

All the testing was done repeatedly at the 7 th, 14th and 21th day after unilateral administration of lactacystin; sham-operated and saline-injected animals were tested at the same time points.

\section{Histological Examination}

The animals were anesthetized by an intravenous injection of chloral hydrate $(300 \mathrm{mg} / \mathrm{kg}$, i.p.) and perfused transcardially with $0.9 \%$ saline followed by $4 \%$ buffered formaldehyde. The brains were removed, blocked, immersed in the same fixative for $24 \mathrm{~h}$, and then placed in saline with the addition of $30 \%$ sucrose until the block sank. They were then sectioned coronally with a cryostat (RM2015, Leica, Germany) at a thickness of $50 \mu \mathrm{m}$. Sections were collected in sequence; 2 series were collected onto gelatincoated slides. The sections were deparaffinized and rehydrated. After $3 \% \mathrm{H}_{2} \mathrm{O}_{2}$, the sections were washed with phosphate-buffered saline (PBS; ZLI-9062, Beijing Zhongshan Golden Bridge Biotechnology Co., Ltd., China) and incubated in citrate buffer (0.1 M, pH 5.8), then repeatedly washed with PBS for immunohistochemistry.

Sections were immersed in a solution of $10 \%$ normal goat serum and $1 \%$ bovine serum albumin (made up with PBS) for $1 \mathrm{~h}$. Alternate sections were then incubated in anti-tyrosine hydroxylase (TH, 1:500; Sigma-Aldrich Corp.) or rabbit polyclonal anti$\alpha$-synuclein antibody (1:200; Beijing Zhongshan Golden Bridge Biotechnology Co., Ltd. ) overnight at $4^{\circ} \mathrm{C}$. Thereafter, the sections were incubated with biotinylated anti-mouse for $15 \mathrm{~min}$ at room temperature. Finally, sections were incubated in the avidinbiotin-peroxidase complex for $15 \mathrm{~min}$ at room temperature. The bound peroxidase molecule was visualized using 3,3'-diaminobenzidine (DAB; Sigma). Between incubations, the sections were washed several times with PBS. Each of the antibodies, together with the avidin-biotin-peroxidase complex, was diluted with PBS. Sections were mounted on gelatin-coated slides, dried overnight, dehydrated in ascending alcohols, cleared in Histoclear and coverslipped with DPX. For control experiments, the antibodies were replaced by $\mathrm{PBS}$ and then reacted as above. Control sections were immunonegative.

The number of dopaminergic cells was counted using TH immunoreactivity. This method was used to explore whether cell loss after lactacystin treatment was due to loss of antigen expression $(\mathrm{TH})$; in other words, whether there was a functional (TH) cell loss [14]. 
The number of cells in the midbrain on each side of the brain was counted from 10 sections in each case ( 1 section every 5 sections from midbrain in sequence). The total number of cells in 10 sections in each animal was counted. Counts were made from comparable sections across the rostrocaudal extent of the ventral SNc. This region is the most clearly defined part of the nucleus and hence formed the focus of our analysis. This study did not endeavor to report on the total number of cells in the SNc of rats. Rather, the number of cells in the same nucleus of corresponding sections in different individual cases was compared. This strategy has been used in many recent studies examining issues similar to this study $[14,16]$. The optical density (OD) of $\alpha$-synuclein aggregates was assessed with the Image Processing System of Olympus BX51 from the above 10 sections, generating the mean OD value of $\alpha$-synuclein in residual TH neurons. Symmetric areas to injected sides and sham-lesioned as well as saline-treated controls were compared.

The SNc specimens were carefully dissected and fixed in $2.5 \%$ glutaric dialdehyde for $2 \mathrm{~h}$, and washed 3 times with PBS for 15 min. Then, the specimens were postfixed in $2 \%$ osmic acid for $1 \mathrm{~h}$. After three 15-min washes with PBS and one 15-min wash with $50 \%$ alcohol, the specimens were immersed in saturated uranyl acetate overnight. At last, the specimens were dehydrated in ethyl alcohol, embedded in Epon-Araldite, and cut on an ultramicrotome. The ultrathin sections were examined with a transmission electron microscope (Jeol, Japan).

\section{Statistical Analyses}

Microsoft Excel software was used for all analyses. Results are given as mean \pm SEM. The multiple comparisons of behavioral and histological data in lactacystin lesions, sham lesions and control animals were done by ANOVA followed by Dunn's post hoc analysis. Nonparametric data were compared using a nonparametric ANOVA test followed by Dunn's post hoc analysis. The numbers of TH-positive cells and rotations as well as the OD of $\alpha$-synuclein aggregates in lactacystin lesions, sham-lesions and control animals were compared by one-way ANOVA followed by two independent-sample t test post hoc analysis. Pearson's product-moment correlation coefficient was applied for analysis of the degree of correlation between the behavioral, SPECT and histological data and the level of significance was also obtained. A probability level of $5 \%(\mathrm{p}<0.05)$ was considered significant.

\section{Results}

\section{Spontaneous Behavioral Changes}

Usually, patients with PD are first identified by their behavioral abnormalities, so it was essential to investigate the behavioral changes in our experimental study of PD. All the animals completed the tests except for 1 animal in the lactacystin-treated group; we thus achieved an exceedingly high success rate. In the first postoperative week, a unilateral injection of lactacystin into the $\mathrm{SNc}$ induced the following behavioral changes: locomotor activity reduction, tardy dyskinesia, trembling and heteronomous piloerection, compared with the sham-operat- ed and control rats, and these symptoms augmented from 7 to 21 days. Nothing obvious happened in the shamoperated and control animals.

To investigate the asymmetry of the dopamine circuit in the bilateral nigrostriatal circuit, we did the typical rotation test induced by APO. APO is a dopamine receptor agonist which can stimulate both classes of dopamine receptors $\left(D_{1}, D_{2}\right)$ and can therefore directly affect presynaptic or autoreceptors and postsynaptic or heteroreceptors. In the first study of its kind [16], it was found that APO administered at $0.05 \mathrm{mg} / \mathrm{kg}$ led to contraversive turning. Furthermore, the induction of contralateral turning occurred within several minutes after APO injection. As contralateral turning reached its peak frequency within minutes, declined gradually thereafter and halted about $45 \mathrm{~min}$ after the injection, the present experiment recorded the rotational behaviors of animals treated unilaterally with lactacystin or saline for $30 \mathrm{~min}$ 10 min after the injection.

The challenge with intraperitoneal APO hydrochloride, $0.5 \mathrm{mg} / \mathrm{kg}$, for $30 \mathrm{~min}$ was performed at days 7,14 and 21 after the microinfusions. Contralateral turning was readily observed. During turning, the pattern of stepping is apparently asymmetrical, that is, the forepaw ipsilateral to the lesion was found to step sideways, whereas the contralateral forepaw was stretched away and pulled along [17]. Since the contralateral hind paw remained stationary, the rat actually turned around this paw ('pivoting'). Meanwhile, its head touched its tail, curving like a cycle rotating at a rapid speed. Thus, the ipsilateral forelimb appeared to determine the pattern and direction of stepping whereas the contralateral limbs were mostly akinetic.

In the present study, we demonstrated that lactacystin-treated rats turned contralaterally to the lesion and this behavior became gradually more severe. The number of rotations was observed on postoperative days 7, 14 and 21 for $30 \mathrm{~min}(\mathrm{~F}=19.115, \mathrm{p}<0.001)$ whereas, the rotational behavior was observed in the sham-operated and control animals (fig. 1).

\section{Behavior in the Open Field \\ Locomotion}

In the lactacystin-treated animals, the shuttling distance within 15 min was less than in the saline-treated group, so was the rearing. Those animals became dull, and their total resting time increased, compared with the saline-treated animals. Concerning the sham-operated animals without treatment, all the indexes were identical to the saline-treated group. 


\section{Hypokinetic Signs}

There was no obvious difference in the sham-operated and control animals for shuttling distance and total time of ambulation and ceasing for the whole duration of the experimentation. However, as far as lactacystin-treated animals are concerned, the deteriorations of shuttling distance (fig. $2 \mathrm{a}, \mathrm{F}=35.694, \mathrm{p}<0.001$ ) and total time of ambulation (fig. $2 \mathrm{~b}, \mathrm{~F}=13.877, \mathrm{p}<0.001$ ) were statistically significantly time-dependent. With respect to total ceasing time in lactacystin-treated animals, the increasing of ceasing time also exhibited a statistically significant time dependence (fig. $2 c, F=42.583, p<0.001$ ).

\section{Asymmetrical Signs}

There was no obvious difference between left and right quarter turns in the sham-operated and control animals. But the number of ipsilateral quarter turns was larger than contralateral quarter turns. This symptom was worsening at day 7, 14 and 21 after operations, e.g. left quarter turns (fig. $2 \mathrm{~d}, \mathrm{~F}=11.301, \mathrm{p}=0.001$ ) and right quarter turns (fig. $2 \mathrm{~d}, \mathrm{~F}=15.999, \mathrm{p}<0.001$ ).

With respect to leaning against the walls in rearing, lactacystin-treated animals depended on left forelimbs more than on right ones compared with the sham-operated and control animals. Additionally, this behavior became more severe with time. There was no difference in the number of times the animal leant against wall with its left forelimb than with its hind limbs in lactacystintreated animals (fig. $2 \mathrm{e}, \mathrm{F}=0.554, \mathrm{p}=0.592$ ). However, a highly significant difference was observed for the right forelimb (fig. 2e, $\mathrm{F}=7.276, \mathrm{p}=0.006$ ).

In contrast to the sham-operated and control animals, the lactacystin-treated animals showed a significant difference in the number of exploratory activities with the right trunk closing to the wall (fig. $2 \mathrm{f}, \mathrm{F}=12.286, \mathrm{p}=$ 0.001 ), with no significant difference shown for the number of exploratory activities with the left trunk closing to the wall (fig. $2 \mathrm{f}, \mathrm{F}=1.45, \mathrm{p}=0.266$ ).

\section{Lactacystin Treatment Causes Neuronal}

Degeneration in $\mathrm{SNc}$

In figure 3, representative pictures show the loss of dopaminergic cells ipsilateral to the microinfused SNc. The amount of cell loss was significant in the ipsilateral SNc. There was no cell loss in saline-treated animals and animals without any treatment. In lactacystintreated animals, the number of TH-positive cells was abundant in the contralateral SNc and was the same as that in the control groups, but the number of TH-positive cells decreased significantly in the ipsilateral lesion,

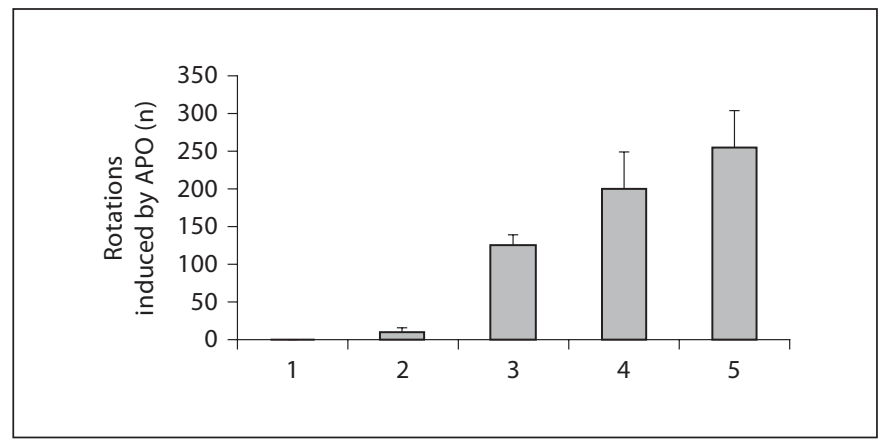

Fig. 1. Lactacystin-induced rotation of rats. $1=$ Sham-operated animals (left SNc intact); 2 = control animals; 3,4 and $5=$ up to 7,14 and 21 days after administration of lactacystin, respectively. There is a statistically significant difference between lactacystintreated animals $(\mathrm{F}=19.115, \mathrm{p}<0.001)$ and sham-operated and control animals.

with some collapsing and dim structures revealed by light microscopy.

$\mathrm{TH}$-positive cell counts from the ipsilateral SNc of sham-operated and control animals were 623.67 and 619.29 , respectively $(\mathrm{p}>0.05)$. Inversely, the numbers of TH-positive cells in the left and right SNc were 129.33 and 621.45 , respectively, in the lactacystin-treated animals ( $\mathrm{p}<0.05$ ), a highly significant difference (fig. $4, \mathrm{~F}=$ $185.443, \mathrm{p}<0.01)$. Furthermore, the number of TH-positive cells in the left $\mathrm{SNc}$ was reduced by $79.19 \%$ compared with the right side; this reduction was time-dependent.

In sham-operated and control animals, the TH-positive nerve fibers from the ipsilateral striatum were plentiful. With respect to lactacystin-treated animals, the THpositive nerve fibers of the ipsilateral striatum were becoming rare, with weaker immunostaining (fig. 5).

\section{Lactacystin Treatment Induces $\alpha$-Synuclein Aggregation}

Consistent with the reported staining pattern of $\alpha$ synuclein in lactacystin-treated cell cultures [7], we found that $\alpha$-synuclein immunostaining was diffused in control nigral tissue whereas it clustered in nigral tissue ipsilateral to the microinfused SNc, suggestive of its aggregation as visualized by light microscopy (fig. 6), with gradual increases in OD of $\alpha$-synuclein aggregates ( $\mathrm{F}=$ 47.732, $\mathrm{p}<0.01)$.

\section{The Ultrastructural Changes in SNc}

In contrast to control tissues, lactacystin-treated SNc tissues developed $\alpha$-synuclein-immunopositive aggregates as revealed by light microscopy (fig. 6). By trans- 


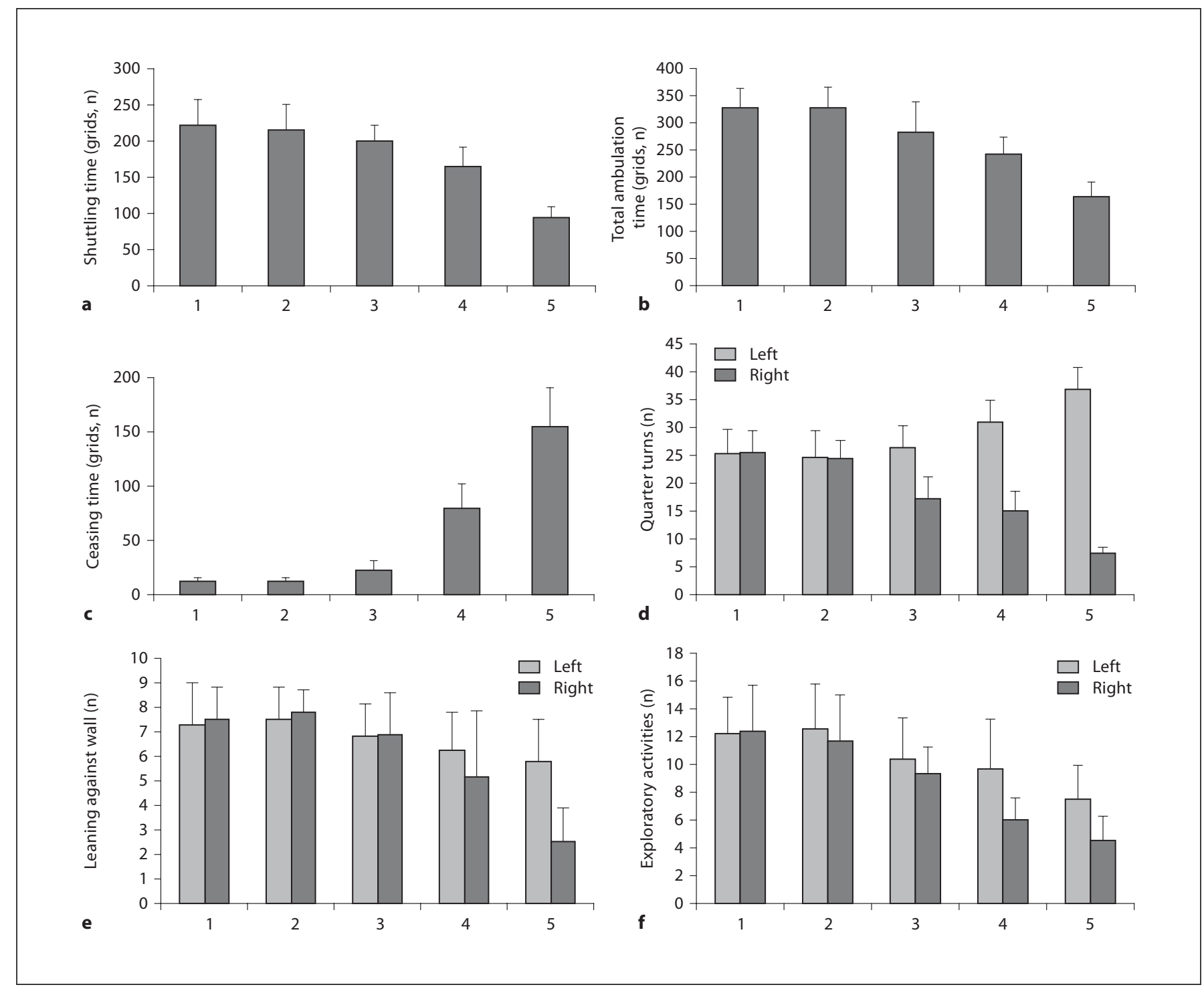

Fig. 2. Behavioral changes in the open-field test. $1=$ Sham-operated animals (left SNc intact); $2=$ control animals; 3,4 and $5=$ up to 7,14 and 21 days after administration of lactacystin, respectively. a Total shuttling time (grids) $(\mathrm{F}=35.694, \mathrm{p}<0.001)$. b Total ambulation time (grids) $(\mathrm{F}=13.877, \mathrm{p}<0.001)$. c Total ceasing time (grids) $(\mathrm{F}=42.583, \mathrm{p}<0.001)$. $\mathbf{d}$ Number of quarter turns to the left $(\mathrm{F}=11.301, \mathrm{p}=0.001$ in lactacystin-treated animals $)$ and to the right $(\mathrm{F}=15.999, \mathrm{p}<0.001$ in lactacystin-treated animal $)$.

e Number of resting against the wall with the left forelimb ( $\mathrm{F}=$ $0.554, \mathrm{p}=0.592$ in lactacystin-treated animals) and the right fore$\operatorname{limb}(\mathrm{F}=7.276, \mathrm{p}=0.006$ in lactacystin-treated animals $)$ when standing on hindlimbs. $\mathbf{f}$ Number of exploratory activities with left $(\mathrm{F}=1.450, \mathrm{p}=0.266$ in lactacystin-treated animal $)$ and right $(\mathrm{F}=12.286, \mathrm{p}=0.001$ in lactacystin-treated animals) trunk closing to box wall in the open-field test.

mission electron microscopy (TEM), these intracellular aggregates were shaped and structured as electron-dense whorls which possessed a core along with multilamellar fibril whorls peripherally, which may be protein aggregates in the ecphyma (fig. 7h).

By TEM, we also observed changes in cellular organelles and DA neurons in SNc. In control groups, the DA

neurons in the SNc have intact caryotheca, limpid nucleoli and normal structures of mitochondria (fig. 7a). Glial cells in the SNc also exhibited a normal structural morphology (fig. 7b). The fine structure of myelin sheaths was limpid (fig. 7c). However, ipsilateral to the lesion in lactacystin-injected animals, most of the surviving DA neurons showed typical apoptotic signs, e.g. caryotheca 
Fig. 3. Loss of $\mathrm{TH}$ neurons in $\mathrm{SNc}$ in response to lactacystin treatment. $\times 400$. a Left $\mathrm{SNc}$ after lactacystin treatment. Cell loss measured by counting HE-stained cells was significant compared with the contralateral SNc. b Right SNc after injection of lactacystin into the left SNc: the number of TH-positive neurons was abundant. c SNc in control animals was similar to the right $\mathrm{SNc}$ of lactacystin-treated rats. d Left SNc in sham-operated animals: numerous TH-positive neurons may be seen; no difference was found in the neural tissue compared with $\mathbf{b}$ and $\mathbf{c}$.
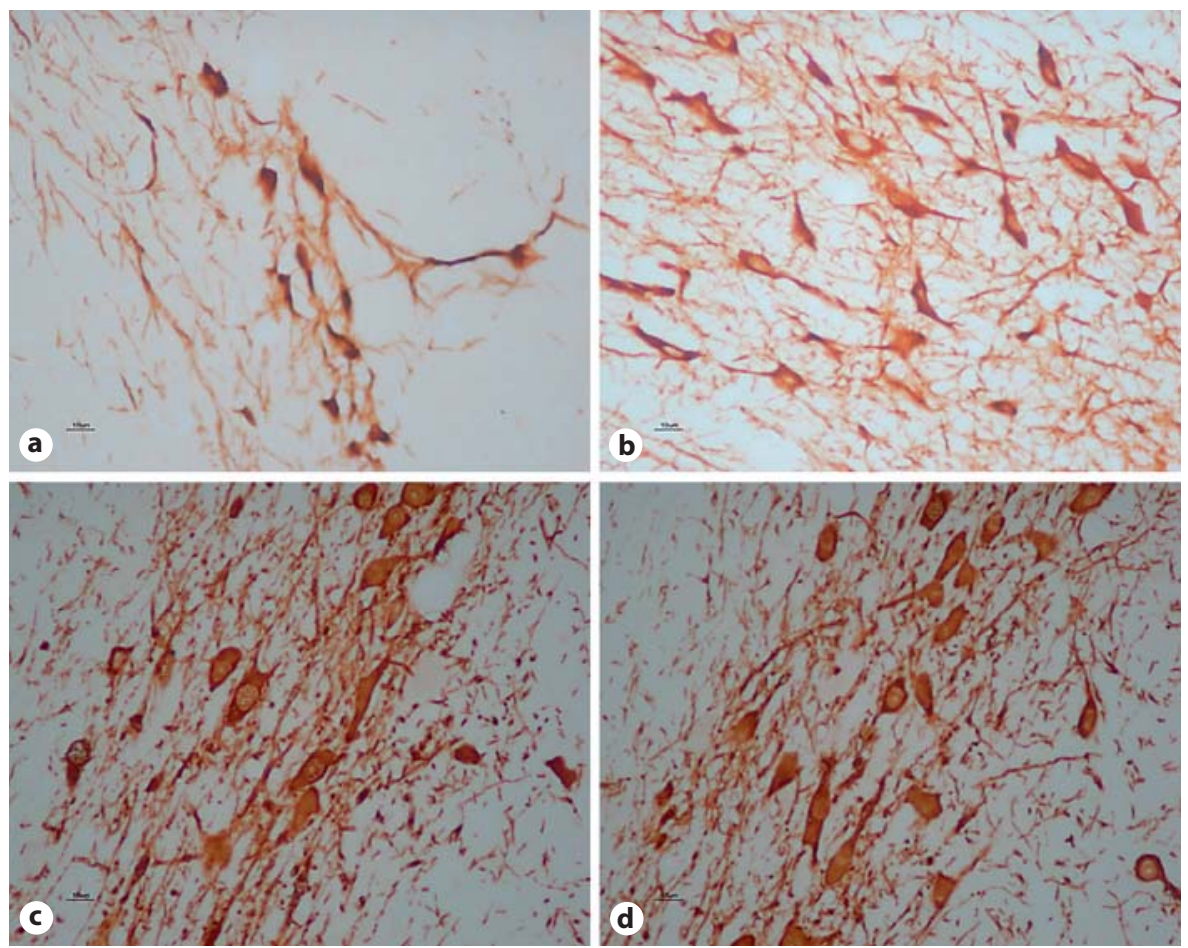

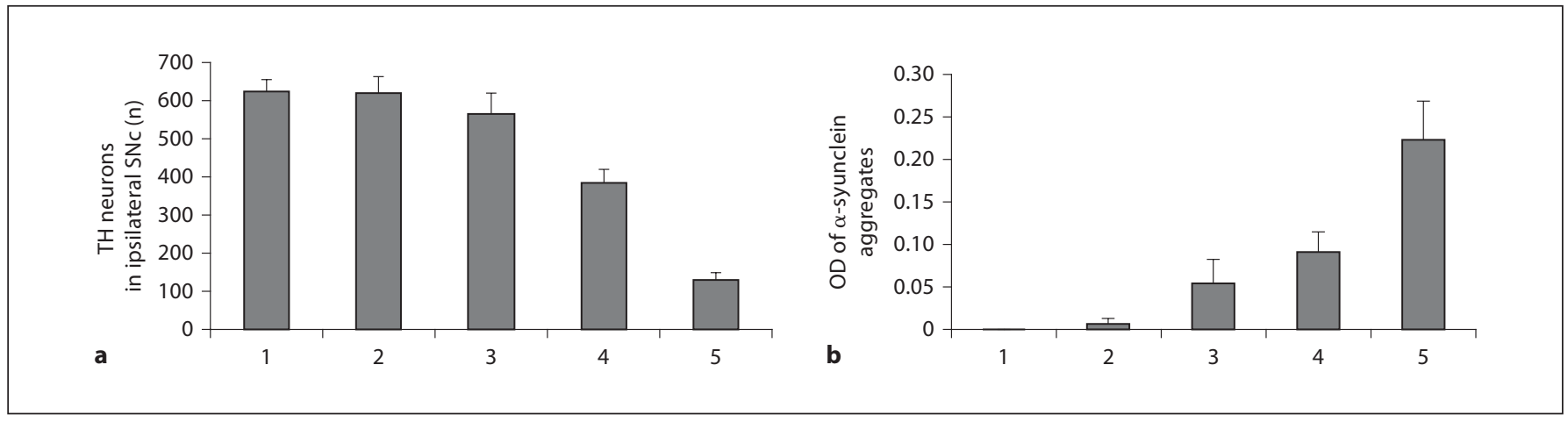

Fig. 4. Number of TH neurons $(\mathbf{a}, \mathrm{F}=185.443, \mathrm{p}<0.01)$ and $\mathrm{OD}$ of $\alpha$-synuclein aggregates $(\mathbf{b}, \mathrm{F}=47.732, \mathrm{p}<$ 0.01) in the ipsilateral SNc. 1 = Sham-operated animals (intact left SNc); 2 = saline-treated animals; 3,4 and $5=$ up to 7, 14 and 21 days after administration of lactacystin, respectively.

exhibiting shrinkage, rugosity and partial fragmentation, with intranuclear chromatin condensed by margination. In addition, a bulk of mitochondria in the intracytoplasm were swollen and denatured, even with vacuolization (fig. 7d). Several glial cells also showed apoptotic signs (fig. 7e). The fine structure of most myelin sheaths became loose and most probably displayed fragmentation (fig. 7f). Occasionally, the medullary shell also exhibited structural degeneration, e.g. ecphyma swelling and coarsening with a number of pronounced electrondense whorls (fig. $7 \mathrm{~g}$ ).

\section{Correlative Studies}

$\mathrm{TH}$ neuron counts and OD of $\alpha$-synuclein aggregates in the ipsilateral SNc of lactacystin-treated animals were significantly correlated ( $\mathrm{r}=-0.819, \mathrm{p}=0.046)$ (fig. 8). Interestingly, as shown in figure 9 , there was a strong, highly significant correlation between $\alpha$-synuclein ag- 
Fig. 5. Loss of TH-positive nerve fibers in corpus striatum of lactacystin-treated rats. $\times 400$. a Left side injected with lactacystin; the staining decreased severely compared with the contralateral corpus striatum. b Right corpus striatum of lactacystintreated rats; TH staining is strong, compared with a. c The expression on the left corpus striatum in control animals is the same as on the right in lactacystin-treated animals. d Left corpus striatum in shamoperated animals: strong TH-positive expression, no difference was found compared with $\mathbf{b}$ and $\mathbf{c}$.
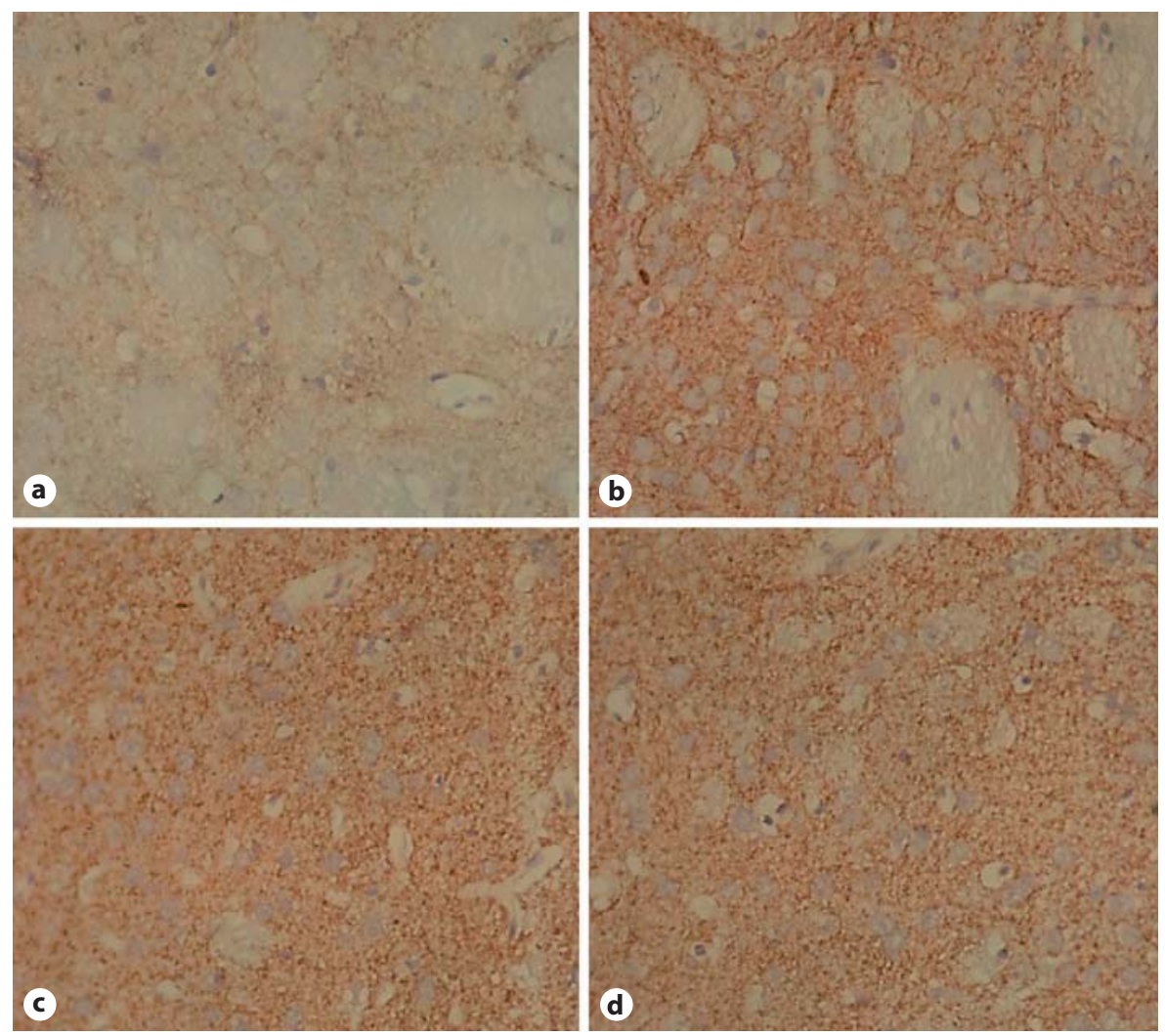

Fig. 6. Increased expression and aggregation of $\alpha$-synuclein in SNc after lactacystin treatment. $\times 400$. a SNc of sham-operated and control animals showing diffuse $\alpha$ synuclein aggregates in the neural tissue. b Left SNc treated with lactacystin: clustered $\alpha$-synuclein aggregates in the neural tissue compared with sham-operated and control expression (a).

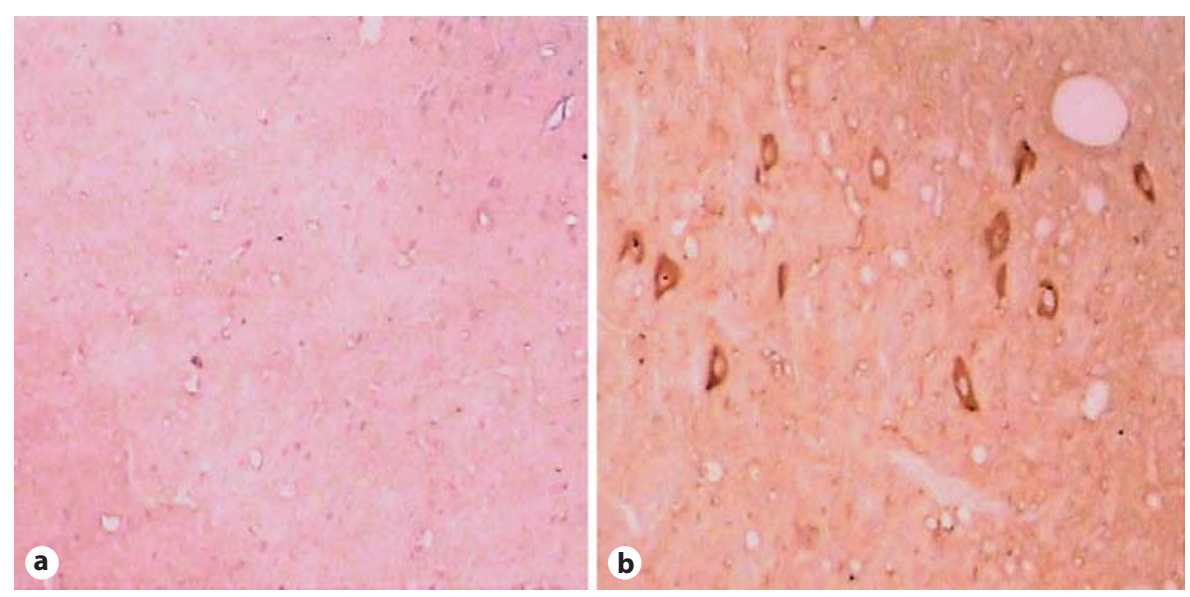

gregates in the ipsilateral SNc of lactacystin-treated animals and behavioral changes, i.e. the correlation with total ceasing time $(\mathrm{r}=0.878, \mathrm{p}=0.021)$, total shuttling time $(\mathrm{r}=0.926, \mathrm{p}=0.008)$, total ambulation time $(\mathrm{r}=-0.956$, $\mathrm{p}=0.003)$, number of contralateral rotations following APO $(r=0.993, p=0.007)$, number of exploratory activities $(\mathrm{r}=-0.915, \mathrm{p}=0.01)$, and number of spontaneous right quarter turns $(\mathrm{r}=-0.909, \mathrm{p}=0.012)$. In contrast, $\mathrm{TH}$ neuron counts in the ipsilateral SNc of lactacystintreated animals were not correlated with behavioral changes, i.e. total ceasing time $(r=-0.721, p=0.106)$, total shuttling time $(r=-0.624, p=0.186)$, total ambulation time $(r=0.446, p=0.375)$, number of rotations following unilateral treatment with APO $(r=-0.534, p=0.275)$, 

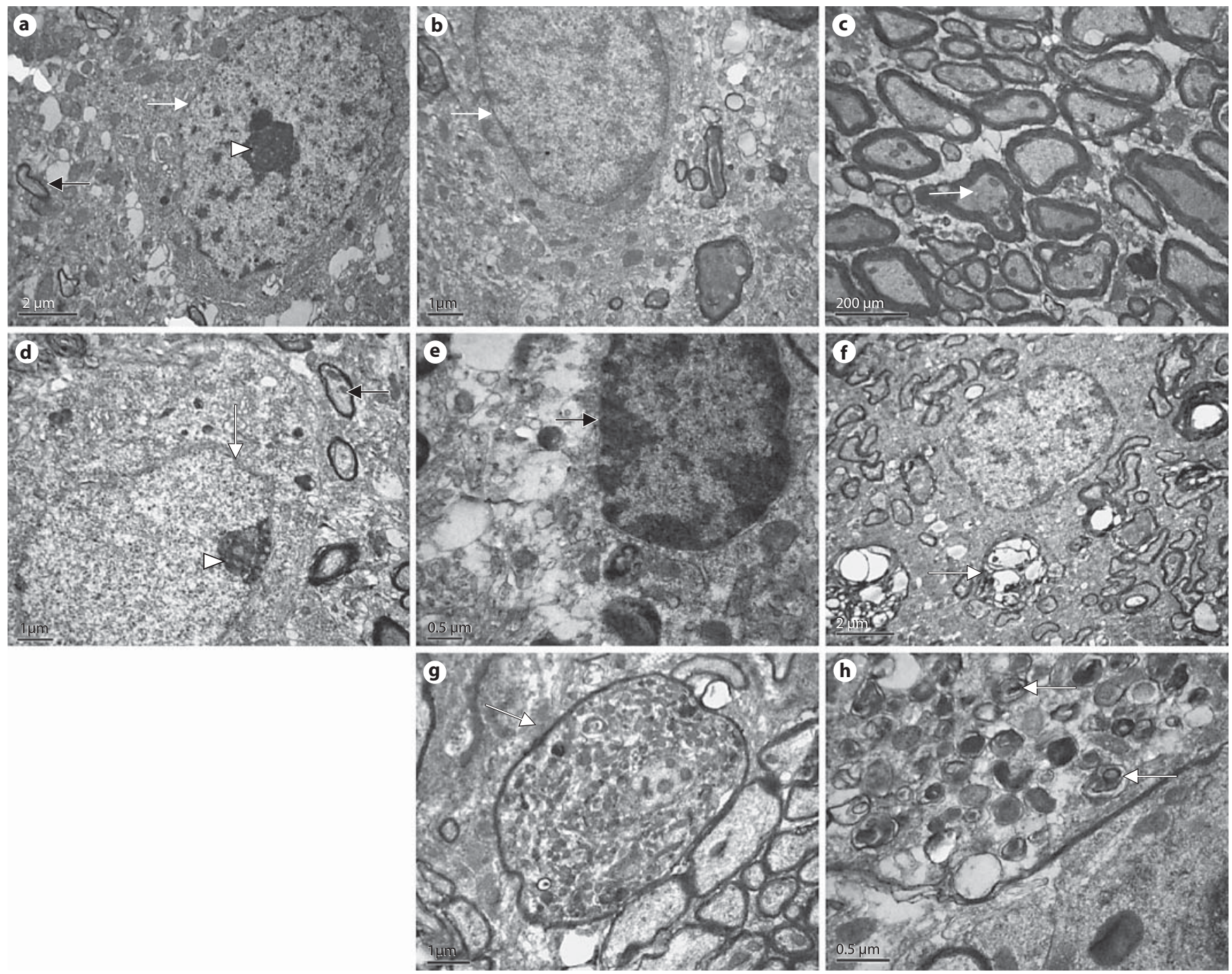

Fig. 7. Ultrastructural changes in the SNc of lactacystin-treated rats. a The neurons of the right SNc of the rats microinfused with lactacystin in the left $\mathrm{SNc}$ showed intact caryotheca (white arrow), limpid nucleoli (arrowhead) and a normal mitochondrial structure (black arrow). b Glial-cell structural morphology was normal and the fine structure of the myelin sheath was limpid in the right $\mathrm{SNc}$ of the rats microinfused with lactacystin into the left SNc (c). d Sites ipsilateral to the SNc microinfused with lactacystin: most surviving neurons display apoptotic signs, e.g. caryotheca (white arrow) exhibiting shrinkage, rugosity and partial fragmentation, with intranuclear chromatin condensed by margination (arrow- head), typical of apoptotic cells. In addition, mitochondria (black arrow) in the intracytoplasm were swollen and denatured, even with vacuolization. Several glial cells also showed apoptotic signs (e), and the fine structure of most myelin sheaths became loose and exhibited clear fragmentation (f). Medullary shells also show structural degeneration, e.g. ecphyma swelling and coarsening and a large number of whorls of pronounced electron density $(\mathbf{g})$. h Electron-dense whorl with a core along with whorls with multilamellar fibrils peripherally, which may be protein aggregations ( $\alpha$-synuclein) in the ecphyma. number of spontaneous right quarter turns $(r=0.809$, $\mathrm{p}=0.051$ ), excluding a correlation with the number of exploratory activities $(\mathrm{r}=0.814, \mathrm{p}=0.049)$, possibly due to the small number of animals in which $\mathrm{TH}$ data were available.

\section{Discussion}

The ubiquitin-proteasome system is responsible for $>80 \%$ of the intracellular protein degradation in eukaryotes, including two components: the ubiquitin-conjugat- 


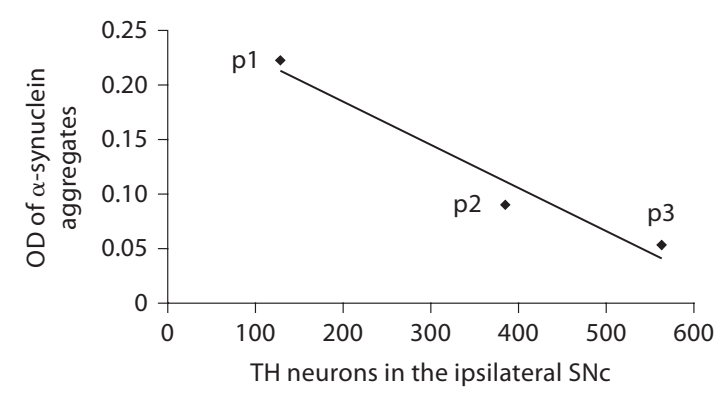

Fig. 8. Correlation between TH neurons counts (x-axis) and the $\mathrm{OD}$ of $\alpha$-synuclein aggregates (y-axis) in the ipsilateral $\mathrm{SNc}$ of lactacystin-treated animals $(\mathrm{r}=-0.819, \mathrm{p}=0.046) . \mathrm{p} 1, \mathrm{p} 2$ and p3 = Up to 7, 14 and 21 days after lactacystin administration, respectively.

ing system and the $26 \mathrm{~S}$ proteasome $[7,8,18]$. UPS-mediated proteolysis is essential to regulate the half-lives of proteins involved in cell cycle regulation, transcriptional control, antigen processing, angiogenesis, and removal of incorrectly folded or damaged proteins $[19,20]$. In the present study, we investigated pathological changes and behavioral changes in a lactacystin-induced model of PD.

\section{Lactacystin-Induced Model of PD}

In 2001 McNaught and Jenner [4] were the first to report impaired proteasomal function in postmortem substantia nigra of patients with idiopathic PD. The same group [8] used lactacystin, a proteasome inhibitor, to investigate proteasomal function in rat ventral mesencephalic cultures and found that an impaired proteasome system causes dopaminergic cell death and Lewy body formation. Meanwhile, Rideout et al. [7] showed for the first time that lactacystin caused proteasome inhibition in PC12 cells, a dopaminergic cell line, and created a cellular model of PD. Thus, they reproduced the two hallmarks of Lewy body disease, i.e. cell death and formation of cytoplasmic inclusions, in PC12 and VM cultures, in keeping with typically pathological characters of PD. After that, many experimental models of PD were devised that used lactacystin and other proteasome inhibitors injected into the striatum and/or SNc. Three years later, McNaught et al. [21], in particular, were successful in creating an animal model of PD through systemic administration of lactacystin. Subsequently, the same results were successfully reproduced by other groups [22, 23]; however, some studies obtained contrasting results with sys- temic administration of lactacystin [16, 24-26]. Therefore, we created a model using a stereotactic approach for injection of lactacystin into the SNc. Other neurotoxin-based models treating animals by different routes were developed: the 1-methyl-4-phenyl-1,2,3,6-tetrahydropyridine (MPTP) model (no typical Lewy bodies) [27-29], the first effective model for neuroscientists to study PD; the 6-hydroxydopamine model (without Lewy bodies) [16, 30]; the rotenone model (variable individual susceptibility) [31,32] or mouse $\alpha$-synuclein overexpression (no loss of dopaminergic neurons in SNc) [33].

In the present study, we found that lactacystin injection in vivo into the $\mathrm{SNc}$ at doses producing a significant plateau inhibition of proteasome activity $(10 \mu \mathrm{g} / 2 \mu \mathrm{l})$ causes neuronal damage and behavioral alterations mimicking the clinical and pathological characters of PD.

\section{Behavioral Changes after Lactacystin Treatment}

With respect to the rotation test in lactacystin-treated rats, we observed the occurrence of the rotational behavior just 1 week after injection. Rotation testing demonstrated an asymmetry on the dopamine circuit, which was clearly displayed in the bilateral nigrastriatal tract. Simultaneously, we found that the rotational behaviors to the contralateral side became more severe with time. This is in agreement with previous studies [34, 35]. In the quantitative recording, we found that the number of rotations to the contralateral side was $266.92 \pm 9.19$, thus achieving the rotational standard of the PD model with $>7$ rotations/min or 210 rotations/30 min at day 21 after the operation $[34,35]$.

Lactacystin-induced behavioral changes reflecting other indexes could also be observed by open-field testing [12, $15,36]$. In the present study, we firstly detected general and specific locomotion changes between the lactacystin-, saline-treated and normal animals. One week after lactacystin injection, the moving and rearing behaviors of animals began to decrease, including head and limb movements; these alterations became gradually more marked and were similar to the clinical characteristics of PD, in contrast to the alterations observed after rotenone administration (variable individual susceptibility) [33]. As concerns the manifestations of asymmetrical locomotor responses, in contrast to the lactacystin-treated animals, there was a difference neither in the number of turns to the ipsilateral or the contralateral side nor in the rearing and exploratory behaviors in the saline-treated and normal animals, and the results were also consistent with the previous studies $[34,35]$. Especially, all the locomotor behaviors showed a trend to the left, i.e. there was an obvious imbalance be- 


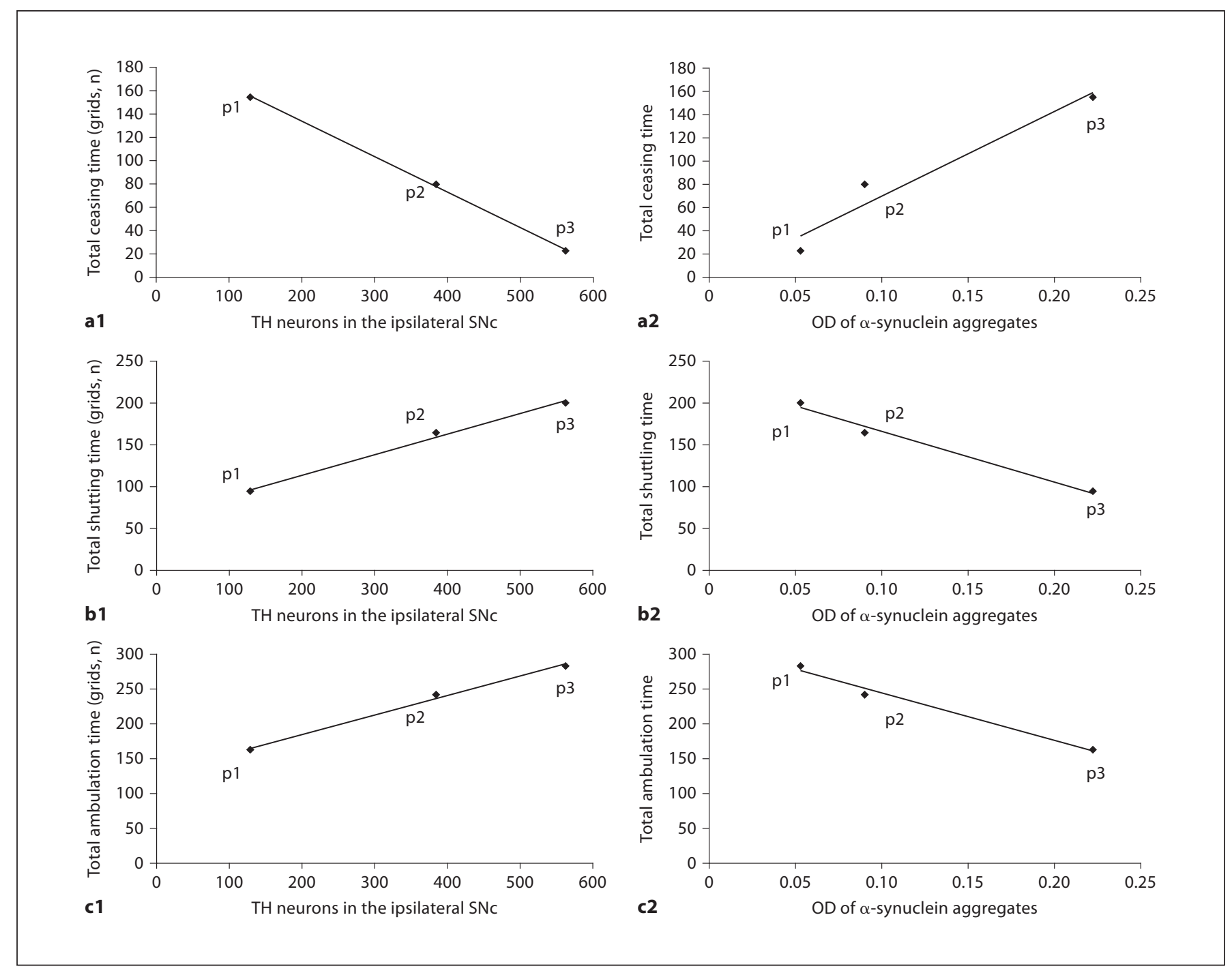

Fig. 9. Correlation between behavioral changes and histopathologic changes in lactacystin-treated animals. p1, p2 and p3 $=\mathrm{Up}$ to 7, 14 and 21 days after lactacystin administration, respectively. a1 Correlation between TH neuron counts (x-axis) and total ceasing time ( $\mathrm{y}$-axis) in lactacystin-treated animals $(\mathrm{r}=-0.721, \mathrm{p}=$ 0.106). a2 Correlation between the OD of $\alpha$-synuclein aggregates (x-axis) and total ceasing time (y-axis) in lactacystin-treated animals $(r=0.878, p=0.021)$. b1 Correlation between TH neuron counts (x-axis) and total shuttling time (y-axis) in lactacystin-

tween the left and the right. The behaviors were also similar those in the 6-OHDA and MPTP animal models of PD $[36,37]$, further indicating an asymmetry of the DA circuit in the nigra-striatal tract. In the present study, we also investigated in detail for the first time time-dependent cataplasia of behaviors, which were in keeping with late progressive characteristics of $\mathrm{PD}$. It is reasonable to assume treated animals $(\mathrm{r}=-0.624, \mathrm{p}=0.186)$. $\mathbf{b 2}$ Correlation between the OD of $\alpha$-synuclein aggregates ( $\mathrm{x}$-axis) and total shuttling time ( $y$-axis) in lactacystin-treated animals $(r=0.926, p=0.008)$. c1 Correlation between TH neuron counts (x-axis) and total ambulation time (y-axis) in lactacystin-treated animals $(\mathrm{r}=0.446$, $p=0.375)$. c2 Correlation between the OD of $\alpha$-synuclein aggregates (x-axis) and total ambulation time (y-axis) in lactacystintreated animals $(r=-0.956, p=0.003)$. that the ubiquitin-proteasome system could play an essential role in the pathogenesis of PD.

\section{Pathological Changes in the SNc and Striatum after} Lactacystin Treatment

$\alpha$-Synuclein is a major protein component in Lewy bodies and Lewy neurites in sporadic PD, whose overex- 


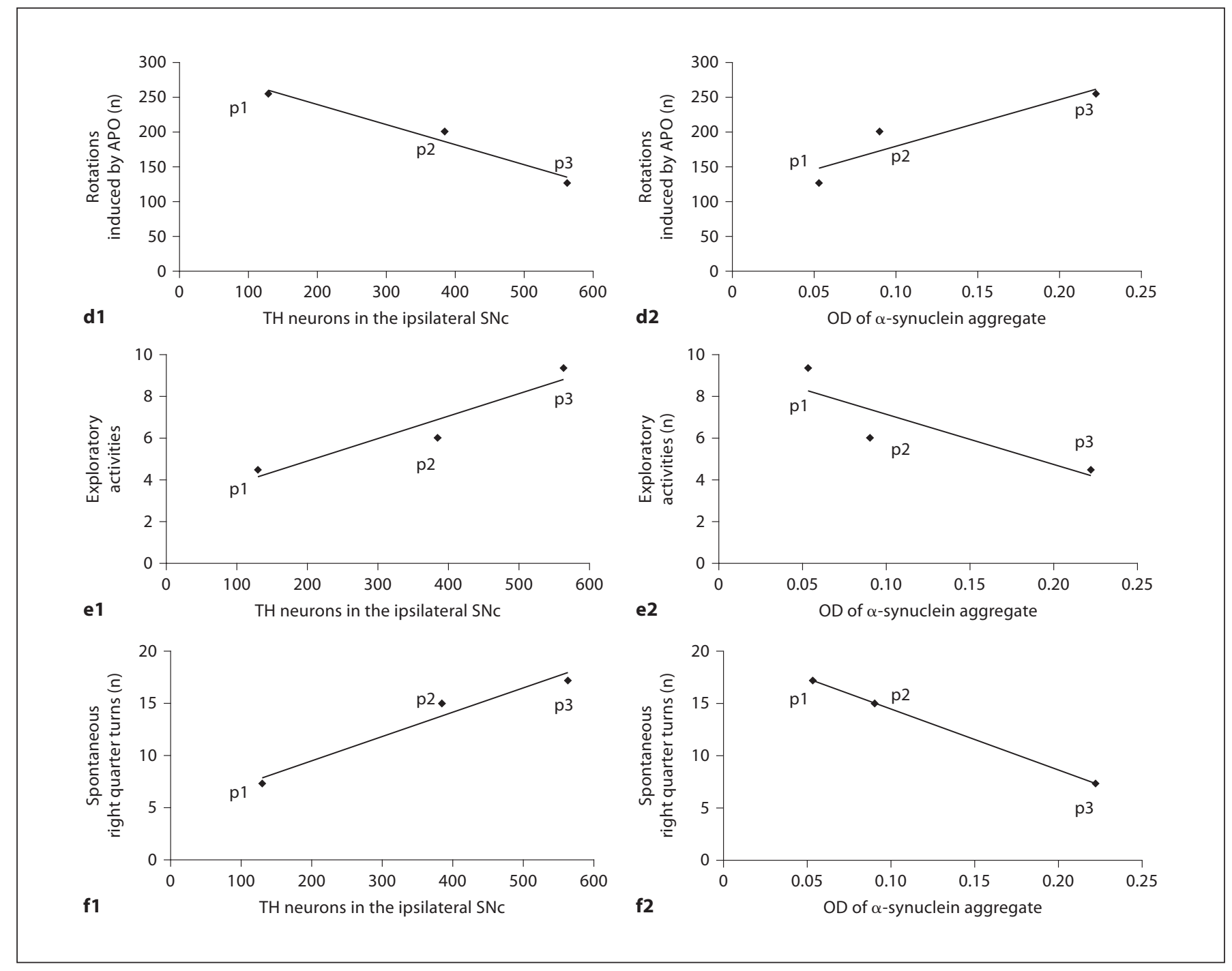

Fig. 9. d1 Correlation between TH neuron counts (x-axis) and the number of rotations following unilateral administration of APO (y-axis) in lactacystin-treated animals $(r=-0.534, p=0.275) . d 2$ Correlation between the OD of $\alpha$-synuclein aggregates (x-axis) and the number of rotations following unilateral administration of APO (y-axis) in lactacystin-treated animals ( $\mathrm{r}=0.993, \mathrm{p}=$ 0.007). e1 Correlation between TH neuron counts (x-axis) and number of exploratory activities (y-axis) in lactacystin-treated animals $(r=0.814, p=0.049)$. $\mathbf{2} 2$ Correlation between the OD of

pression results in degeneration of dopaminergic neurons and motor deficits in Drosophila melanogaster and transgenic mice [38-40]. Simultaneously, the presence of Lewy bodies was considered as one of the pathological hallmarks in PD [3]. In the present study, we found intense intracytoplasmic accumulation of $\alpha$-synuclein in lactacystin-treated SNc by light microscopy and TEM $\alpha$-synuclein aggregates ( $\mathrm{x}$-axis) and the number of exploratory activities ( $y$-axis) in lactacystin-treated animals $(r=-0.915, p=$ 0.01). f1 Correlation between TH neuron counts ( $\mathrm{x}$-axis) and the number of spontaneous right quarter turns (y-axis) in lactacystintreated animals $(r=0.809, p=0.051) . \mathbf{f} 2$ Correlation between OD of $\alpha$-synuclein aggregates (x-axis) and the number of spontaneous right quarter turns ( $y$-axis) in lactacystin-treated animals $(r=$ $-0.909, \mathrm{p}=0.012$ ).

compared with control groups. However, MPTP [41, 42] and 6-OHDA [30] animal models of PD also exhibited loss of TH neurons, but they did not have typical Lewy bodies. This is not in accord with the pathological characteristics of PD. In addition, we also observed other ultrastructural changes in SNc, and further identify pathological degeneration of SNc treated with lactacystin. 
In addition, McNaught et al. [9] also observed a dosedependent degeneration of dopaminergic cell bodies. Here, we subjected the time-dependent decrease in $\mathrm{TH}$ neurons and morphological cataplasia of TH neurons to statistical and histological analyses which demonstrated the toxicity of $\alpha$-synuclein to dopaminergic neurons. Simultaneously, immunostaining revealed that TH-positive nerve fibers also became rare in the ipsilateral striatum of lactacystin-treated animals, and their mean OD value exhibited a statistically significant decrease compared with the control group. Thus, it may be reasonable to speculate that failure of protein degradation by proteasome inhibitor results in massive accumulation of $\alpha$ synuclein in striatonigral neuron terminals in the SNc.

\section{Correlation between Pathological Changes and}

\section{Behavioral Data after the Operation}

The present study clearly demonstrates the changes in pathological and behavioral data. However, the correlation between histopathological findings and behavior has seldom been reported systematically and in detail to date, especially in the lactacystin model of PD. In the present study, we firstly found a strong, highly significant correlation between $\alpha$-synuclein aggregates in the ipsilateral SNc of lactacystin-treated animals and behavioral changes, i.e. a correlation with total shuttling time $(\mathrm{r}=0.926, \mathrm{p}=0.008)$, total ambulation time $(\mathrm{r}=-0.956, \mathrm{p}=0.003)$, number of rotations to the contralateral side following APO treatment $(\mathrm{r}=0.993, \mathrm{p}=0.007)$ and number of exploratory activities $(\mathrm{r}=-0.915, \mathrm{p}=0.01)$. However, no correlation was found between TH neuron counts in the ipsilateral SNc of lactacystin-treated animals and behavioral changes, notably with total ceasing time $(\mathrm{r}=-0.721, \mathrm{p}=0.106)$ and total shuttling time $(\mathrm{r}=-0.624, \mathrm{p}=0.186)$. Thus behavioral changes were chiefly due to $\alpha$-synuclein aggregation rather than to a decrease in TH neurons. Simultaneously, there was a significant correlation between $\mathrm{TH}$ neuron counts and the OD of $\alpha$-synuclein aggregates in the ipsilateral SNc of lactacystin-treated animals $(\mathrm{r}=-0.819, \mathrm{p}=0.046)$. These observations emphasize that the cataplasia of $\mathrm{TH}$ neurons and behavioral changes were caused by $\alpha$-synuclein aggregation, which is the etiopathogenetic factor of PD. The accumulation of $\alpha$-synuclein aggregates reflect the failure of the proteasome system, which has become unable to eliminate the aggregates promptly and efficiently, and induced organelle apomorphosis resulting in degeneration and apoptosis as well as necrosis of TH neurons in the SNc, spured behavioral changes ultimately causing clinical symptoms such as locomotor activity reduction, late dyskinesia, trembling and heteronomous piloerection.

\section{Conclusion}

Taken together, all these studies show a tight association between an impaired ubiquitin-proteasome system and the occurrence of selective damage to the nigrostriatal pathway featured by subcellular alterations similar to PD. Impairment of the ubiquitin-proteasome system may lead to the formation and accumulation of $\alpha$-synuclein protein, causing mitochondrial vacuolization, disruption of the respiratory chain resulting in a lack of ATP; the aggregation of $\alpha$-synuclein aggravates the failure of the ubiquitin-proteasome system. This creates a vicious cycle which induces cell loss and, eventually, the development of pathological symptoms. The correlation between $\alpha$ synuclein aggregation and behavioral changes made it obvious that $\alpha$-synuclein aggregates stimulate the development of behavioral deteriorations. Thus PD is caused by a blockade of the ubiquitin-proteasome system by $\alpha$ synuclein aggregation. Improvement of the function of the ubiquitin-proteasome system would eliminate more proteinaceous aggregates accumulated in the organism, and the $\alpha$-synuclein aggregates found in cells and the whole organism. Research would contribute to the development of novel therapeutic strategies for improving symptom management and blocking disease progression in PD and other neurodegenerative diseases associated with the failure of the ubiquitin-proteasome system in vivo.

\section{Acknowledgements}

This work was supported by the Science and Technological Fund of Anhui Province for Outstanding Youth, China (grant No. 04043072) and the Fund of Talent Development of Anhui, China (grant No. 2006Z037)

References

\footnotetext{
1 Dauer W, Przedborski S: Parkinson's disease: mechanisms and models. Neuron 2003; 39:889-909.

2 About-Sleinman PM, Muqit MM, Wood NW: Expanding insights of mitochondrial dysfunction in Parkinson's disease. Nat Rev Neurosci 2006;7:207-219.

3 Wood-Kaczmar A, Gandhi S, Wood NW: Understanding the molecular causes of Parkinson's disease. Trends Mol Med 2006;12: 512-518.

4 McNaught KS, Jenner P: Proteasomal function is impaired in substantia nigra in Parkinson's disease. Neurosci Lett 2001;297: 191-194.
} 
5 McNaught KS, Belizaire R, Jenner P, Olanow $\mathrm{CW}$, Isacson O: Selective loss of $20 \mathrm{~S}$ proteasome $\alpha$-subunits in the substantia nigra pars compacta in Parkinson's disease. Neurosci Lett 2002;326:155-158.

-6 McNaught KS, Belizaire R, Isacson O, Jenner P, Olanow CW: Altered proteasomal function in sporadic Parkinson's disease. Exp Neurol 2003;179:38-46.

-7 Rideout HJ, Larsen KE, Sulzer D, Stefanis L: Proteasomal inhibition leads to formation of ubiquitin/ $\alpha$-synuclein-immunoreactive inclusions in PC12 cells. J Neurochem 2001;78: 899-908.

-8 McNaught KS, Mytilineou C, Jnobaptiste R, Yabut J, Shashidharan P, Jennert P, Olanow $\mathrm{CW}$ : Impairment of the ubiquitin-proteasome system causes dopaminergic cell death and inclusion body formation in ventral mesencephalic cultures. J Neurochem 2002; 81:301-306.

-9 McNaught KS, Björklund LM, Belizaire R, Isacson $\mathrm{O}$, Jenner $\mathrm{P}$, Olanow CW: Proteasome inhibition causes nigral degeneration with inclusion bodies in rats. Neuroreport 2002;13:1437-1441.

10 Fornai F, Lenzi P, Gesi M, Ferrucci M, Lazzeri G, Busceti CL, Ruffoli R, Soldani P, Ruggieri S, Alessandri MG, Paparelli A: Fine structure and biochemical mechanisms underlying nigrostriatal inclusions and cell death after proteasome inhibition. J Neurosci 2003; 23:8955-8966.

11 Bao XM, Shu SY: The Stereotaxic Atlas of the Rat Brain. Beijing, People's Medical Publishing House, 1991.

12 van Oosten RV, Cools AR: Differential effects of a small, unilateral, 6-hydroxydopamine-induced nigral lesion on behavior in high and low responders to novelty. Exp Neurol 2002;178:245-255.

13 Nikolaus S, Huston JP, Körber B, Thiel C, Schwarting RK: Pretreatment with neurokinin substance $\mathrm{P}$ but not with cholecystokinin-8S can alleviate functional deficits of partial nigrostriatal 6-hydroxydopamine lesion. Peptides 1997;18:1161-1168.

- 14 Lundblad M, Andersson M, Winkler C, Kirik D, Wierup N, Cenci MA: Pharmacological validation of behavioural measures of akinesia and dyskinesia in a rat model of Parkinson's disease. Eur J Neurosci 2002;15: 120-132.

-15 Fornaguera J, Schwarting RK: Early behavioral changes after nigro-striatal system damage can serve as predictors of striatal dopamine depletion. Prog Neuropsychopharmacol Biol Psychiatry 1999;23:1353-1368.

16 Ungerstedt U: Postsynaptic supersensitivity after 6-hydroxy-dopamine induced degeneration of the nigro-striatal dopamine system. Acta Physiol Scand Suppl 1971;367:69-93.

$\checkmark 17$ Marshall JF, Richardson JS, Teitelbaum P: Nigrostriatal bundle damage and the lateral hypothalamic syndrome. J Comp Physiol Psychol 1974;87:808-830.

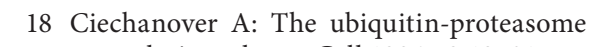
proteolytic pathway. Cell 1994;79:13-21.

19 Baumeister W, Walz J, Zühl F, Seemüller E: The proteasome: paradigm of a self-compartmentalizing protease. Cell 1998;92:367380.

20 Lee AH, Iwakoshi NN, Anderson KC, Glimcher LH: Proteasome inhibitors disrupt the unfolded protein response in myeloma cells. Proc Natl Acad Sci USA 2003;100:99469951.

21 McNaught KS, Perl DP, Brownell AL, Olanow CW: Systemic exposure to proteasome inhibitors causes a progressive model of Parkinson's disease. Ann Neurol 2004;56:149162.

22 Zeng BY, Bukhatwa S, Hikima A, Rose S, Jenner P: Reproducible nigral cell loss after systemic proteasomal inhibitor administration to rats. Ann Neurol 2006;60:248-252.

23 Schapira AH, Cleeter MW, Muddle JR, Workman JM, Cooper JM, King RH: Proteasomal inhibition causes loss of nigral tyrosine hydroxylase neurons. Ann Neurol 2006; 60:253-255.

24 Kordower JH, Kanaan NM, Chu Y, Suresh Babu R, Stansell J 3rd, Terpstra BT, Sortwell CE, Steece-Collier K, Collier TJ: Failure of proteasome inhibitor administration to provide a model of Parkinson's disease in rats and monkeys. Ann Neurol 2006;60:264268.

25 Manning-Boğ AB, Reaney SH, Chou VP, Johnston LC, McCormack AL, Johnston J, Langston JW, Di Monte DA: Lack of nigrostriatal pathology in a rat model of proteasome inhibition. Ann Neurol 2006;60:256260.

26 Bové J, Zhou C, Jackson-Lewis V, Taylor J, Chu Y, Rideout HJ, Wu DC, Kordower JH, Petrucelli L, Przedborski S: Proteasome inhibition and Parkinson's disease modeling. Ann Neurol 2006;60:260-264.

27 Burns RS, Chiueh CC, Markey SP, Ebert MH, Jacobowitz DM, Kopin IJ: A primate model of parkinsonism: selective destruction of dopaminergic neurons in the pars compacta of the substantia nigra by $\mathrm{N}$-methyl-4-phenyl1,2,3,6-tetrahydropyridine. Proc Natl Acad Sci USA 1983;80:4546-4550.

28 Langston JW, Forno LS, Rebert CS, Irwin I: Selective nigral toxicity after systemic administration of 1-methyl-4-phenyl-1,2,5,6tetrahydropyrine (MPTP) in the squirrel monkey. Brain Res 1984;292:390-394.

29 Jenner P, Rupniak NM, Rose S, Kelly E, Kilpatrick G, Lees A, Marsden CD: 1-Methyl-4phenyl-1,2,3,6-tetrahydropyridine-induced parkinsonism in the common marmoset. Neurosci Lett 1984;50:85-90.

-30 Sauer H, Oertel WH: Progressive degeneration of nigrostriatal dopamine neurons following intrastriatal terminal lesions with 6 hydroxydopamine: a combined retrograde tracing and immunocytochemical study in the rat. Neuroscience 1994;59:401-415.
31 Betarbet R, Sherer TB, MacKenzie G, GarciaOsuna M, Panov AV, Greenamyre JT: Chronic systemic pesticide exposure reproduces features of Parkinson's disease. Nat Neurosci 2000;3:1301-1306.

32 Greenamyre JT, Betarbet R, Sherer TB: The rotenone model of Parkinson's disease: genes, environment and mitochondria. Parkinsonism Relat Disord 2003;9:S59-S64.

-33 Masliah E, Rockenstein E, Veinbergs I, Mallory M, Hashimoto M, Takeda A, Sagara Y, Sisk A, Mucke L: Dopaminergic loss and inclusion body formation in $\alpha$-synuclein mice: implications for neurodegenerative disorders. Science 2000;287:1265-1269.

- 34 Perese DA, Ulman J, Viola J, Ewing SE, Bankiewicz KS: A 6-hydroxy-dopamineinduced selective parkinsonian rat model. Brain Res 1989;494:285-293.

35 Hefti F, Melamed E, Wurtman RJ: Partial lesions of the dopaminergic nigrostriatal system in rat brain: biochemical characterization. Brain Res 1980;195:123-137.

-36 Schwarting RK, Huston JP: The unilateral 6-hydroxydopamine lesion model in behavioral brain research. Analysis of functional deficits, recovery and treatments. Prog Neurobiol 1996;50:275-331.

37 Ashkan K, Wallace BA, Mitrofanis J, Pollo C, Brard PY, Fagret D, Benabid AL: SPECT imaging, immunohistochemical and behavioural correlations in the primate models of Parkinson's disease. Parkinsonism Relat Disord 2007;13:266-275.

38 Auluck PK, Chan HY, Trojanowski JQ, Lee VM, Bonini NM: Chaperone suppression of $\alpha$-synuclein toxicity in a Drosophila model for Parkinson's disease. Science 2002;295: 865-868.

39 Chen L, Feany MB: $\alpha$-Synuclein phosphorylation controls neurotoxicity and inclusion formation in a Drosophila model of Parkinson disease. Nat Neurosci 2005;8:657-663.

40 Lee MK, Stirling W, Xu Y, Xu X, Qui D, Mandir AS, Dawson TM, Copeland NG, Jenkins NA, Price DL: Human $\alpha$-synuclein-harboring familial Parkinson's disease-linked Ala$53->$ Thr mutation causes neurodegenerative disease with $\alpha$-synuclein aggregation in transgenic mice. Proc Natl Acad Sci USA 2002;99:8968-8973.

- 41 Burns RS, Chiueh CC, Markey SP, Ebert MH, Jacobowitz DM, Kopin IJ: A primate model of parkinsonism: selective destruction of dopaminergic neurons in the pars compacta of the substantia nigra by $\mathrm{N}$-methyl-4- phenyl1,2,3,6-tetrahydropyridine. Proc Natl Acad Sci USA 1983;80:4546-4550.

-42 Langston JW, Forno LS, Rebert CS, Irwin I: Selective nigral toxicity after systemic administration of 1-methyl-4-phenyl-1,2,5,6tetrahydropyrine (MPTP) in the squirrel monkey. Brain Res 1984;292:390-394. 